\title{
Special issue: The Economics of Ageing, Selected Papers from the 2012 Annual Meeting of the Austrian Economic Association
}

\author{
Alexia Prskawetz $\cdot$ Inga Freund $\cdot$ Bernhard Rengs
}

Published online: 18 June 2013

(C) Springer Science+Business Media New York 2013

Increasing life expectancy and low birth rates are shaping the future of the European population. The economic consequences of demographic ageing are manifold. At the individual level, a longer, healthy lifespan will affect microeconomic decisions including education, employment, savings, investments and retirement. Institutional conditions (family, labour and pension policies for example) will influence these decisions together with prevailing norms, values and the economic situation. At the aggregate level, population ageing implies an increasing share of people at older ages and a declining share of young and working-age people. This change in the age structure of the population will have a decisive impact on the labour market, aggregate consumption, savings and investment patterns, and productivity as well as on the redistribution of resources within and between generations. The retirement of the baby-boom generation will further intensify these effects. At the same time the changing age structure will have an impact on the compensation of labour, physical and human capital. Politicians have to face the profound implications with regard to public spending on pensions, health, long-term care and education. Confronted with this major multi-faceted challenge, the question arises how to fundamentally sustain economic well-being.

Faced with the economic challenges caused by population ageing and in reference to the 2012 European Year for Active Ageing and Solidarity between

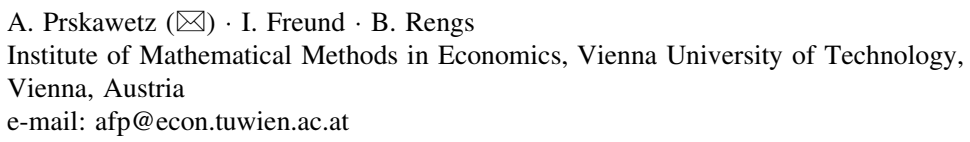

\section{A. Prskawetz}

Vienna Institute of Demography, Austrian Academy of Sciences,

Vienna, Austria

A. Prskawetz

Wittgenstein Centre for Demography and Global Human Capital, Vienna, Austria 
Generations, the key theme of the Austrian Economic Association's 2012 annual meeting was chosen to address "The Economics of Ageing". The conference was organized by the Research Group Economics at the Institute of Mathematical Methods in Economics, Vienna University of Technology, on 18-19 May 2012. Overall the conference comprised 28 sessions with a total of 96 papers. From those papers relevant to the main topic of the conference a selection was submitted to the special issue of Empirica among which a final set of six papers was accepted for publication. In addition the keynote speech by Axel Börsch-Supan is included in the special issue.

In his keynote, Axel Börsch-Supan clearly indicates the challenges (economic growth and fiscal sustainability) and the benefits (longer and healthier lives) of individual and population ageing. He then focuses particularly on the interlink between three policy areas: pension systems, health care systems and labour markets, arguing that they are linked through labour supply and economic growth. However, the general public is often reluctant to endorse reforms in these policy areas as these reforms are often badly presented. Moreover, the reforms themselves initiate behavioural reactions that may ultimately either work for or against them. Distorting income taxes or alternative pathways to leave the labour force may be detrimental to reforms that aim at increasing the labour force participation. To quote from the keynote, "A rule of thumb which works quite well in my own country is that about one-third of the effects you think you will get won't happen because people escape." In order to judge the success of any reform, these behavioural reactions need to be taken into account in economic models that aim at simulating the economic consequences of population ageing. Based on Italy, Germany and France, such a simulation model is presented for a reform of the labour market and the pension system. In particular it is assumed that Germany, Italy and France will reach labour force participation rates similar to the Danish ones within the next 30 years. The simulation results clearly indicate that labour market reforms bringing more people into the labour force have the greatest positive effect on future living standards as measured by per capita consumption. In terms of the pension reforms the simulations indicate that a reform that builds on the savings of the baby-boom generation in contrast to a pay-as-you-go pension system induces a higher living standard. Finally, simulations that take into account behavioural reactions to reforms will show a lower standard of living in the future. Overall the simulations clearly indicate that there are opportunities to be seized in order to cope with the challenge of population ageing. Most importantly the keynote by Axel BörschSupan clearly highlights that reforms in the labour market and pension policy are inevitable but at the same time these reforms need to be communicated to the public in order to minimize or prevent negative behavioural reactions to these reforms. As argued throughout his keynote the labour force participation in older ages-together with pension reforms-are key elements in the question of whether or not population ageing will hamper economic growth.

Related to the fact that population ageing is driven by low fertility, the contribution "Can below-replacement fertility be desirable?" by Striessnig and Lutz discusses the question of whether there is an optimal fertility level. It scrutinizes the commonly used replacement fertility level, i.e., the fertility level that implies a 
constant population size. The authors argue for a normative judgement regarding the question of optimal fertility, the focus being on the optimal societal level of fertility. As the economic objective to be maximized they choose an education-weighted support ratio (defined as the number of the working age population to the dependent population) taking into account educational differences in productivity, labour market entry and exit ages as well as life expectancy. Based on actual demographic and educational projections for Germany, Finland and Bulgaria, a set of simulations is conducted giving the support ratio for various levels of fertility at selected future time points. In terms of a maximization of the support ratio, a value of the fertility below replacement level turns out to be optimal for all scenarios. In a set of sensitivity analyses the dependency of the support ratio on future gains in life expectancy and future changes in the educational distribution is studied. The conclusions to be drawn from this simulation exercise are that population ageing is less of a burden on future economic wellbeing - as measured by the support ratio in this study-if societies are more educated. The authors conclude by stressing the importance to include qualitative dimensions such as education and health in addition to age when considering the optimal level of fertility from a normative point of view.

The economic implications of population ageing for Slovenia are discussed in the contribution by Klaus Weyerstrass and Reinhard Neck, “A Young EU Member's Ageing: Budgetary and Macroeconomic Consequences of Slovenia's Demographic Prospects". While Slovenia showed quite a remarkable economic development in the early years of this century, it was hit severely by the economic and financial crisis of 2007-2009. The public debt to GDP ratio reached a value of $47 \%$ in 2011. Weyerstrass and Neck particularly emphasize the role of the demographic structure for further developments of the government budget in Slovenia, focusing on pension and labour market systems. Using the macroeconometric model SLOPOL (SLOvenian POLicy model), various simulations are presented that vary with respect to the average pension replacement rate, the social security contribution rate and the average pension age. Among these various policy options an increase in the retirement age (assuming that a majority of the additional older workers are employed) and a reduction in the pension replacement rate are named as the most effective ones in terms of reducing the budget deficit and the debt to GDP ratio in the future.

The contribution "On the optimal design of a pension system" by Fehr and Uhde quantifies the efficiency of various institutional designs of an unfunded pension system. A dynamic general equilibrium overlapping generations model, in which households optimally choose labour supply, consumption and asset holdings and are subject to mortality and income risks, constitutes the theoretical framework. Different institutional set-ups of a pay-as-you go pension systems are introduced. As a benchmark scenario, a Beveridgean pension system with a flat benefit is contrasted with a Bismarckian earnings-related benefit system. While the former system will introduce labour supply distortions and liquidity constraints, it constitutes a positive insurance effect for labour market and income risk. The Bismarckian system by contrast will imply lower labour market distortions since the contribution-benefit link is closer, but it will also reduce the insurance against income risk. Simulations 
for the transitional path and the new long-run economic equilibrium indicate that the highest efficiency gains for the Beveridgean pension system are realized at a replacement rate of $40 \%$ of the average labour income. For a Bismarckian pension system the optimal replacement rate is higher, at $60 \%$. The simulations further indicate that the efficiency gains are higher for the Beveridgean as compared to the Bismarckian pension system when the replacement rate is low but the relation reverses with an increase in the replacement rate. However, further sensitivity analyses indicate that the difference in efficiency between these pensions systems may depend on various parameters of the model such as the risk aversion. In a final step the authors introduce two-tier pension systems as a mix of the Beveridgean and Bismarckian system to investigate whether in such a mix, the advantage of each system may be better captured to increase efficiency. They contrast the case where both tiers are implemented independently to each other with the case where the flat benefit rate of the Beveridgean pension system will be reduced in consequence to the introduction of an earnings-related Bismarckian pension benefit (the extent to which the flat benefit is reduced depends on the so-called taper rate). As the various simulations indicate, all two-tier pension systems fall short in terms of efficiency to a benchmark model that only consists of the earnings-related Bismarckian pension system. However, the efficiency gains of a two-tier pension system increase for higher taper rates.

With increasing financial pressure on public-financed pension systems, private pensions gain importance. In the contribution by Bettina Lamla on "Family background and the decision to provide for old age: a siblings approach", the determinants of private pension demand are analyzed. Based on the Riester pension plan introduced in 2001 in Germany, the author studies the role of individual socioeconomic background factors (education and income) on the uptake of Riester pensions. Since these pension systems are quite complicated, social learning may play an important role in an individual's decision to choose supplementary pensions. To capture these social effects, the author studies the role of family background variables and in particular also the role of siblings' decisions on the demand for Riester pensions. More specifically the hypothesis tested is that the likelihood to choose a Riester pension is higher if a family member has already opted for a Riester pension. This effect may decline once a sufficiently large group in the overall population has already bought a Riester pension plan so that the family's importance for the information flow may decline. The data used is the SocioEconomic Panel Study (SOEP) for the years 2004, 2006, 2007 and 2010. Based on a piecewise constant-hazard model the risk of buying a Riester pension is estimated depending on one's siblings' decisions to have already bought a Riester pension and controlling for several socioeconomic and demographic factors. The overall results clearly indicate a correlation with the siblings' decisions to buy a Riester pension which becomes weaker over time as the share of people in the overall population already having a Riester pension increases. In addition, individual characteristics (such as education and income) and family background variables (such as parents' education) are correlated with the uptake of Riester pensions.

Whether private pension schemes are successful is discussed in the contribution by Michael Ziegelmeyer on "Backing out of private pension provision-Lessons 
from Germany". Although about $19 \%$ of all signed Riester contracts have been terminated since 2001, the causes and consequences have not been investigated so far. Based on data of the 2010 SAVE survey in Germany, this study investigates the prevalence and the reasons for terminated and dormant contracts under this pension plan. A particular focus is on the role of household characteristics as well as on income/financial wealth and financial literacy. Since households who actually do terminate or suspend their Riester contracts may not accumulate sufficient savings for old age over time, it is of central importance to gain a better understanding into specific characteristics that may be correlated with these decisions. The descriptive findings indicate that among all those who ended their Riester plan contracts, about $55 \%$ terminated or suspended them due to personal circumstances while the remaining $45 \%$ gave product-related reasons as the cause of their decision. In the latter case the share of households who sign a new contract is larger than in the former case. Overall households with low financial resources, low pension literacy and/or situated in East Germany are more likely to terminate or suspend their contract. As these criteria also cover households facing a higher risk of old-age poverty, it is important to improve the information on private pension plans.

In the final contribution on "The public reallocation of resources across age: A comparison of Austria and Sweden", Bernhard Hammer and Alexia Prskawetz discuss the interrelationship between the economic life cycle and public transfers. Based on data from the National Transfer Accounts (NTA) the article shows how periods of dependency in young and old age are financed through the reallocation of resources. A comparison of the public benefits between Austria and Sweden indicates that in both countries there is a bias towards old-age transfers (as compared to transfers towards the young), though this is more pronounced in Austria than in Sweden. The authors then introduce an economic dependency ratio which is based on the differences between age-specific averages of consumption and labour income-the life cycle deficit. This dependency ratio is weighted by agespecific population numbers and extrapolated into the future based on EUROSTAT population projections, again compared between the two countries. In addition, an economic dependency ratio for the public sector is plotted that relates populationweighted age-specific transfer expenditures to population-weighted age-specific transfer revenues. The results indicate, that though the demographic dependency ratio is higher in Sweden, its economic dependency is lower than in Austria. This can be explained by the different design of the economic life cycle in Sweden with a considerably higher labour force participation in the 55+ age group. 